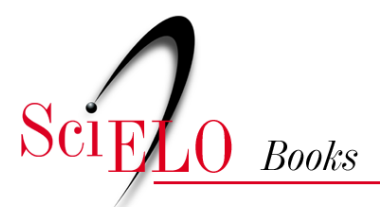

\title{
44. Henrique Aragão, um Nome Festejado na Austrália
}

\author{
Joffre Marcondes de Rezende
}

\section{SciELO Books / SciELO Livros / SciELO Libros}

REZENDE, J. M. Henrique Aragão, um Nome Festejado na Austrália. In: $A$ sombra do plátano: crônicas de história da medicina [online]. São Paulo: Editora Unifesp, 2009, pp. 367-370. História da Medicina series, vol. 2. ISBN 978-85-61673-63-5. https://doi.org/10.7476/9788561673635.0045.

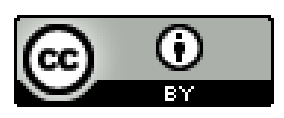

All the contents of this work, except where otherwise noted, is licensed under a Creative Commons Attribution 4.0 International license.

Todo o conteúdo deste trabalho, exceto quando houver ressalva, é publicado sob a licença Creative Commons Atribição 4.0.

Todo el contenido de esta obra, excepto donde se indique lo contrario, está bajo licencia de la licencia Creative Commons Reconocimento 4.0. 


\section{Henrique Aragão, um Nome Festejado na Austrália}

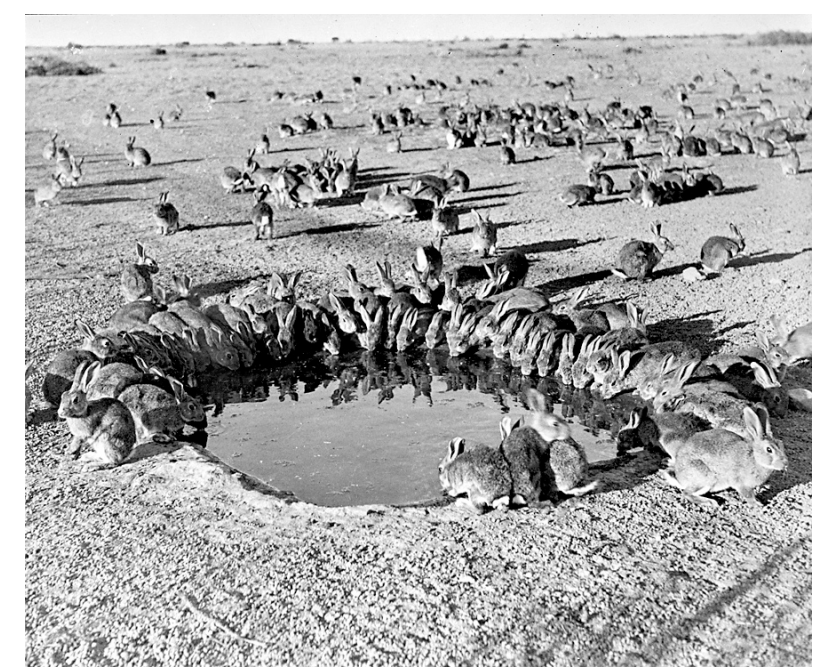

Proliferação de coelhos em Wardang Island, Austrália, 1938.

$\mathrm{D}$ entre os pesquisadores do Instituto Oswaldo Cruz, Henrique de Beaurepaire Rohan Aragão é um nome de destaque na comunidade científica internacional por duas grandes descobertas: o ciclo exoeritrocitário do parasito da malária e a mixomatose do coelho, que permitiu o controle biológico desse roedor na Austrália.

Seu sobrenome francês é de origem materna em terceira geração. Seu avô materno, marechal Henrique de Beaurepaire Rohan, já era brasileiro e teve ativa participação na vida política e cultural da nação, tendo sido cartógrafo e autor de um dicionário de vocábulos brasileiros (Aragão, I986, pp. 375-379).

A vida de Henrique Aragão é parte da história de Manguinhos. Nascido em Niterói em I 879, concluiu o curso médico na Faculdade de Medicina do Rio de Janeiro em I905. A exemplo de Carlos Chagas, desenvolveu sua tese de doutoramento no instituto Oswaldo Cruz, ao qual ligou-se desde 1903, ainda como estudante, ali permanecendo até sua aposentadoria, galgando todas as posições naquela Instituição, desde assistente, chefe de serviço, professor e, finalmente, diretor (Bacellar, I963, pp.I85-I 88). 
Em I907, quando contava 28 anos de idade, ao estudar a malária aviária no pombo realizou sua primeira grande descoberta, a do ciclo exoeritrocitário do hematozoário (Haemoproteus columbae), antecipando a ocorrência de idêntico ciclo na malária humana, o que foi comprovado, trinta anos depois, pelo cientista inglês Percy Garnham ao descrever o ciclo hepático do plasmódio (Aragão, I908, pp. 409-4I6).

Olympio da Fonseca Filho narra que, ao visitar o Instituto de Medicina Tropical de Hamburgo, em I952, ouviu do decano dos protozoologistas alemães, prof. Reichnow, palavras de elogio e admiração pelo trabalho de Henrique Aragão, "tão jovem e já famoso" (Fonseca Filho, I973, p. 43).

Em I909 e I9 Io Aragão realizou estudos na França e na Alemanha, especialmente no Instituto Zoológico de Munique. Ao retornar ao Brasil, dedicou-se inteiramente à pesquisa, interessando-se por diversos campos do conhecimento. Sua produção científica é abrangente e diversificada nas áreas da parasitologia, virologia e biologia em geral. Ocupou-se tanto da pesquisa aplicada aos problemas de saúde pública da época, conforme a orientação do instituto, quanto da pesquisa básica, quando dispunha de tempo.

Trabalhou na profilaxia da malária e desenvolveu estudos sobre a leishmaniose tegumentar, amebíase intestinal, parasitoses do homem e dos animais, febre amarela e outras viroses.

Em I9I I teve sua atenção despertada para o mixoma do coelho, doença letal que acomete esta classe de roedores e que havia sido descrita por Sanarelli em Montevidéu, em i 896. Estudando-a em coelhos de seu laboratório, verificou ser a mesma produzida por um vírus que poderia ser transmitido de um animal a outro pela picada de insetos. Essa descoberta teve repercussão internacional e beneficiou especialmente a Austrália.

Para compreender o alcance da identificação e isolamento do vírus do mixoma do coelho, é necessário conhecer um pouco da história da introdução desse roedor na Austrália e suas consequências.

Em I 859, um inglês, Thomas Austin, que se mudara para a Austrália, importou da Inglaterra 24 coelhos silvestres para que se reproduzissem e ele pudesse continuar a praticar seu esporte preferido - a caça. Os coelhos encontraram na Austrália clima e condições ideais para se reproduzirem e proliferaram de maneira incontrolável, tornando-se uma praga. Devastavam as plantações e a vegetação nativa, competindo com outros mamíferos her- 
bívoros, causando redução dos rebanhos de carneiro e declínio da produção da lã, provocando erosões do solo e diminuição da produção agrícola. A população os combatia pela caça, armadilhas, envenenamento, sem qualquer resultado prático.

Em 1919, Henrique Aragão escreveu ao governo da Austrália, sugerindo o controle biológico, inoculando alguns coelhos com o vírus do mixoma, que ele havia isolado e que se prontificava a fornecer, introduzindo no país uma doença altamente letal para o coelho. As autoridades sanitárias da Austrália relutaram por muitos anos a importar o vírus, temendo consequências imprevistas. Somente em I950, graças a persuasão de cientistas australianos, o governo decidiu autorizar o método proposto por Aragão. Ao final de dezembro de 1950 foram inoculados alguns coelhos que foram soltos. O vírus se espalhou rapidamente pelo país, causando verdadeira epidemia de mixomatose entre os coelhos. A população de roedores, estimada em seiscentos milhões de animais, foi rapidamente reduzida para cerca de cem milhões, permitindo a revegetação do solo e o restabelecimento do equilíbrio ecológico em muitas regiões. Posteriormente, verificou-se queda da mortalidade dos coelhos infectados em $50 \%$, ou por mutação do vírus ou pela imunidade adquirida dos animais.

Em seus estudos sobre a leishmaniose tegumentar, Aragão demonstrou, pela primeira vez, a possibilidade de sua transmissão por flebótomos; ao estudar as doenças eruptivas virais da infância, comprovou que a varicela e o alastrim são causados por vírus distintos; descreveu parasitos de plantas e ainda desenvolveu uma vacina contra a espiroquetose aviária.

Em 1928 surgiu nova epidemia de febre amarela no Rio de Janeiro e Aragão, embora sem êxito, trabalhou exaustivamente na tentativa de produzir uma vacina antiamarílica, chegando a passar noites em seu laboratório em Manguinhos.

Para coroamento de sua carreira, Henrique Aragão foi diretor do Instituto Oswaldo Cruz de 1942 a I949. Em sua administração, o instituto, dando continuidade às propostas do Serviço de Estudo das Grandes Endemias criado por Evandro Chagas, expandiu suas atividades no interior do país com a criação do posto de saúde para estudo da esquistossomose em Pernambuco e o posto para estudo da doença de Chagas, em Bambuí, Minas Gerais, hoje Centro Avançado de Estudos Emmanuel Dias. Neste centro foram feitos 
importantes estudos clínicos e epidemiológicos sobre a tripanossomíase e iniciadas as primeiras experiências de combate aos triatomíneos pela borrifação das casas com inseticidas de ação residual.

Também na sua administração, no período da Segunda Guerra Mundial, o instituto ampliou sua produção industrial de medicamentos e iniciou a fabricação da penicilina. Com a penicilina ali produzida, em ampolas de apenas trezentas unidades, Nery Guimarães descobriu a cura da bouba, hoje praticamente extinta do país.

Aposentado compulsoriamente por idade em I950, Aragão dedicou os últimos anos de sua vida ao estudo e classificação dos ixodídeos (carrapatos). Permaneceu em atividade até uma semana antes de seu falecimento, que se deu a 26 de fevereiro de 1956, aos 77 anos (Aragão, I986).

O Instituto de Medicina Tropical de Hamburgo outorgou-lhe a medalha Nocth, láurea só concedida a cientistas que tenham se destacado por contribuições relevantes à medicina tropical.

O Instituto Oswaldo Cruz possui um pavilhão com o seu nome e o homenageou com dois seminários em sua memória, o primeiro em I979, no centenário de seu nascimento, e o segundo em 2007, em comemoração ao centenário de sua descoberta do ciclo exoeritrocitário do parasito da malária.

\section{Referências Bibliográficas}

Aragão, H. B. A. "Sobre o Ciclo Evolutivo e a Transmissão do Haemoproteus culumbae”. Revista Médica de S. Paulo, I I (20), pp. 409-4I6, I908.

Aragão, M. B. "Henrique de Beaurepaire Rohan Aragão". Cadernos de Saúde Pública, 2 (3), pp. 375-379, I986.

Bacellar, R. C. Brazil's Contribution to Tropical Medicine and Malaria. Rio de Janeiro, Gráfica Olímpica Editora, I963.

Fonseca Filho, O. “A Escola de Manguinhos”. In Falcão, E. C. Oswaldo Cruz. Monumenta Historica. São Paulo, Brasiliensia Documenta, t. I I , I973. 